\title{
Bile acid glycine and taurine conjugates in serum of patients with primary biliary cirrhosis: effect of ursodeoxycholic treatment
}

\author{
Y CHRETIEN, R POUPON, M F GHERARDT, O CHAZOUILLERES, \\ D LABBE, A MYARA, AND F TRIVIN
}

From Unité d'Hépatologie, Hôpital Saint-Antoine, et Laboratoire de Biochimie, Hôpital Saint-Joseph, Paris, France

SUMMARY We have applied a specific and accurate high pressure liquid chromatographic technique to determine fasting serum glycine and taurine conjugates of individual bile acids in patients with primary biliary cirrhosis before and during ursodeoxycholic acid therapy. The study was carried out in nine patients in whom the diagnosis of primary biliary cirrhosis was established according to accepted criteria. After one year of UDCA therapy liver function tests significantly improved. Total serum bile acid concentration did not change significantly (29.2 (31.5) $v 28 \cdot 3(26.4) \mu \mathrm{M})$. Total UDCA $(1.7(2.2) v 13.3(14.5) \mu \mathrm{M})$ and glyco UDCA $(0.8(1.6) v 10.9(11.4 \mu \mathrm{M})$ but not tauro UDCA levels increased significantly $(\mathrm{p}<0.01)$; UDCA $(7 \cdot 7(12.6) v 40.2(12.7) \%)$ became the major species of the circulating bile acids. Primary bile acids $(23(28 \cdot 3) v 11 \cdot 2(10 \cdot 5))$ and their glycoconjugates fell significantly $(p<0 \cdot 01)$. There were no significant changes in the concentrations of conjugates of the secondary bile acids $(4.5(3.8) v 3.9(3.0))$. Our study shows that oral administration of UDCA to patients with primary biliary cirrhosis induced marked changes in the circulating pool of endogenous bile acids together with improvement in liver function test values. The data also suggest that the beneficial effect of longterm administration of UDCA in these patients might be mediated through changes in the circulating primary bile acids and UDCA rather than through changes in the circulating secondary bile acids, deoxycholate and lithocholate.

We found that longterm administration of ursodeoxycholic acid (UDCA) at $13-15 \mathrm{mg} / \mathrm{kg} /$ daily induces marked clinical and biochemical improvement in patients with primary biliary cirrhosis (PBC). ${ }^{1}$ The rationale for the use of UDCA as a potential therapy in $\mathrm{PBC}$ lies on a series of arguments which suggest that some of the hepatic lesions in chronic cholestasis and therefore in PBC could result from intrahepatocellular accumulation of potentially toxic endogenous bile acids such as chenodeoxycholic acid (CDCA) or lithocholic acid (LCA). For example, CDCA and LCA are cytotoxic when incubated with isolated hepatocytes, ${ }^{2}$ when infused parenterally into rodent they cause immediate

Address for correspondence: Professor R Poupon. Unité d'Hépatologie. Hôpital Saint-Antoine, 75012 Paris, France.

Accepted for publication 8 December 1988. cholestasis. ${ }^{34}$ Chenodeoxycholic acid is also hepatotoxic in man, based on bilary analysis in patients who develop evidence of liver injury while ingesting CDCA for cholesterol gall stones dissolution. ${ }^{5}$ In contrast, UDCA is devoid of cytotoxicity. ${ }^{67} \mathrm{We}$ therefore postulated that changes in the composition of the endogenous bile acid pool induced by longterm ingestion of UDCA might be beneficial to patients with PBC. A detailed knowledge of the serum composition of conjugated bile acid in patients with PBC receiving UDCA is of importance for a better understanding of the effects of longterm administration of UDCA. In the present study we applied a specific and accurate high pressure liquid chromatographic technique to determine fasting serum glycine and taurine conjugates of individual bile acids in patients with $\mathrm{PBC}$ before and during UDCA therapy. 


\section{Methods}

PATIENTS

The study was carried out in nine patients (eight women, one man; mean age 54 (8 yrs)). The diagnosis of PBC was established on the following criteria: high serum alkaline phosphatase concentrations; a positive antimitochondrial test; raised serum IgM concentrations; a liver biopsy sample showing lymphoplasmacellular infiltrates with destruction of interlobular ducts or a paucity of bile ducts, and no demonstrable abnormalities of the extrahepatic bile ducts on cholangiogram. Before starting UDCA, all the patients were symptomatic; all had pruritus necessitating the daily or intermittent use of cholestyramine; two had portal hypertension with splenomegaly and oesophageal varices. Histologically, six patients were in stage II and three in stage III. None had cholecystectomy. Ursodeoxycholic was given at a dose of $13-15 \mathrm{mg} / \mathrm{kg}$ body weight per day $(200 \mathrm{mg} /$ capsule, four capsules per day), two capsules at 0800 and 2000 during meals (UDCA, Ursolvan, Synthelabo, France). Each patient underwent detailed clinical and biochemical evaluation before receiving UDCA and every six months thereafter. Two of the patients included in the present study were also among those already reported previously.'

Fasting blood samples for bile acid analysis and routine biochemical tests were taken at $0800-$ that is, in the fasting state 12 hours after the last ingestion of UDCA. For the bile acid analysis, fasting blood samples were centrifuged and stored at $-80^{\circ} \mathrm{C}$ until assay. Serum samples were tested in routine liver biochemical tests by automated techniques. Data at entry into the trial and at one year are presented. After one year of treatment, two patients among the nine included in the study had still pruritus necessitating the intermittent use of cholestyramine.

\section{ANALYTICAL. PROCEDURE OF BII.E ACID} DETERMINATION

The glyco and tauro conjugated primary, secondary, and tertiary bile acids were identified and quantified by a procedure using a combined extraction (Bond Elut and Lipidex 10(0) followed by a HPLC step and a direct spectrophometric detection.

Five hundred microlitres of serum were overloaded by internal standard (diethanolamine fusidate) and diluted by $2 \mathrm{ml}$ of $\mathrm{NAOH} 0 \cdot 10 \mathrm{~N}$. After hydrolysis of conjugated bile acids the mixture was extracted by a combined extraction (Bond Elut and Lipidex 1000)..$^{\text {"We }}$ achieved the procedure by a further treatment of the eluates of Lipidex 1000 with a second Bond Elut filtration which allows to get rid of the residual interferences. This complex extraction is controlled by the addition of an internal standard. The compound allows accuracy for measurement of yield and efficiency of the various steps and clean up of extraction. Tauro and glyco conjugated bile acids were identified by a reverse phase liquid chromatographic step with a mobile phase gradient (carbamate buffer and acetonitrile). Each bile acid was quantified by a direct spectrophotometric detection

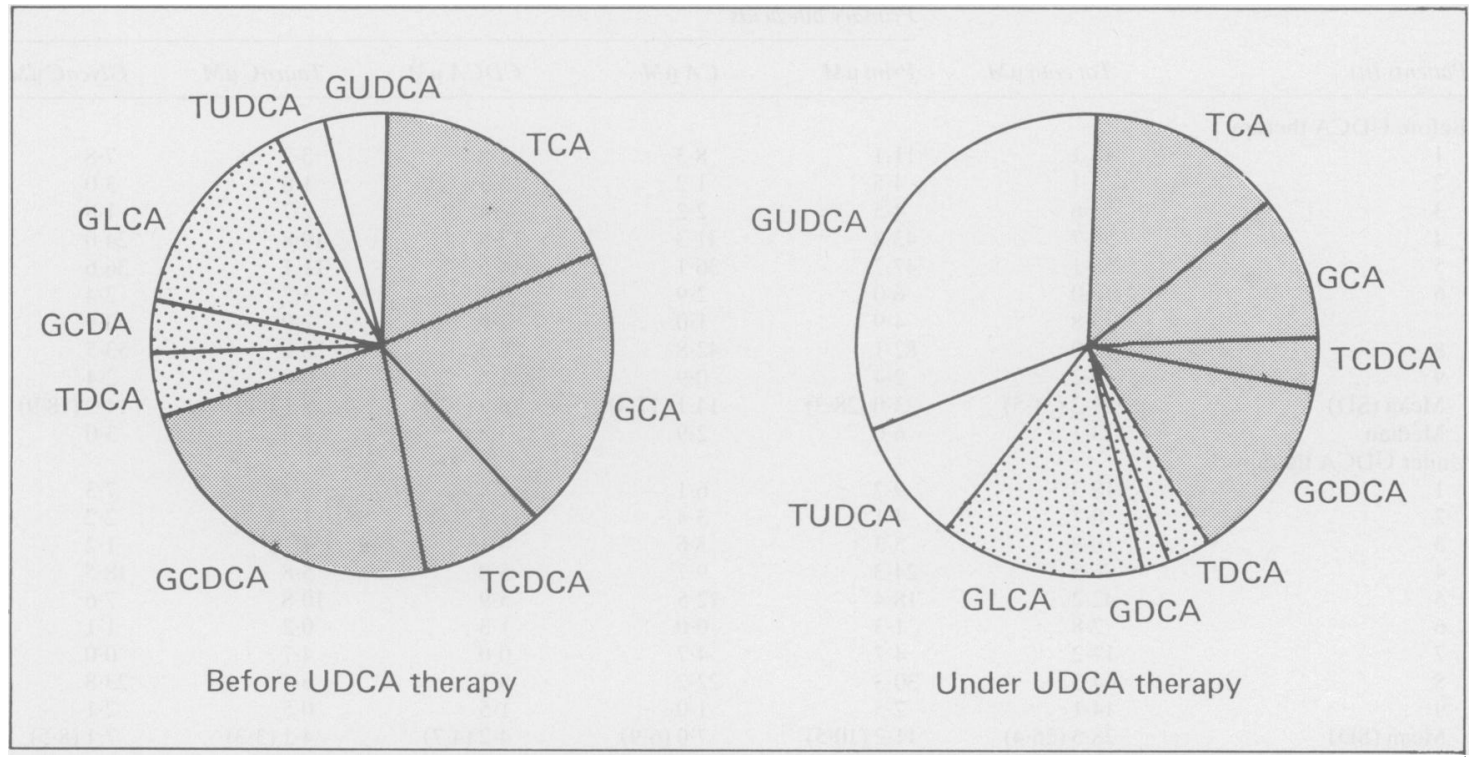

Figure Serum bile acid composition before and under UDCA therapy in patients with primary biliary cirrhosis. 
Table 1 Total bile acid conjugate concentration and proportion of individual species (primary + secondary + tertiary $=100 \%$, of therapy, patients $I$ and 8 had still pruritus requiring intermittent cholestyramine

\begin{tabular}{|c|c|c|c|c|c|c|}
\hline \multirow[b]{2}{*}{ Patients ( $n$ ) } & \multirow[b]{2}{*}{ Tot conj $\mu M$} & \multicolumn{5}{|c|}{ Primary bile acids } \\
\hline & & Prim \% & $C A \%$ & $C D C A \%$ & TauroC $\%$ & GlycoC \% \\
\hline \multicolumn{7}{|c|}{ Before UDCA therapy } \\
\hline 1 & $13 \cdot 1$ & $84 \cdot 6$ & $63 \cdot 2$ & $21 \cdot 4$ & $25 \cdot 2$ & $59 \cdot 4$ \\
\hline 2 & $5 \cdot 1$ & $87 \cdot 7$ & $23 \cdot 4$ & $64 \cdot 3$ & $30 \cdot 2$ & $57 \cdot 5$ \\
\hline 3 & $5 \cdot 6$ & $80 \cdot 9$ & $38 \cdot 6$ & $42 \cdot 3$ & $48 \cdot 8$ & $32 \cdot 1$ \\
\hline 4 & $56 \cdot 7$ & $77 \cdot 2$ & $55 \cdot 2$ & $22 \cdot 0$ & $34 \cdot 8$ & $42 \cdot 4$ \\
\hline 5 & $56 \cdot 1$ & $85 \cdot 0$ & $64 \cdot 3$ & $20 \cdot 7$ & $19 \cdot 7$ & $65 \cdot 3$ \\
\hline 6 & $10 \cdot 0$ & $60 \cdot 0$ & $28 \cdot 8$ & $31 \cdot 3$ & $36 \cdot 5$ & 23.6 \\
\hline 7 & $13 \cdot 8$ & $35 \cdot 2$ & $7 \cdot 3$ & $28 \cdot 0$ & $14 \cdot 5$ & $20 \cdot 7$ \\
\hline 8 & $93 \cdot 0$ & $88 \cdot 2$ & $46 \cdot 0$ & $42 \cdot 2$ & $30 \cdot 7$ & $57 \cdot 5$ \\
\hline 9 & $9 \cdot 2$ & $26 \cdot 3$ & $9 \cdot 5$ & $16 \cdot 9$ & $0 \cdot 0$ & $26 \cdot 3$ \\
\hline Mean (SD) & $29 \cdot 2(31 \cdot 5)$ & $69 \cdot 5(23 \cdot 6)$ & $37 \cdot 3(21 \cdot 6)$ & $32 \cdot 1(15 \cdot 2)$ & $26 \cdot 7(14 \cdot 1)$ & $42 \cdot 8(17 \cdot 5)$ \\
\hline Median & $13 \cdot 1$ & $80 \cdot 9$ & $38 \cdot 6$ & $28 \cdot 0$ & $30 \cdot 2$ & $42 \cdot 4$ \\
\hline \multicolumn{7}{|c|}{ Under UDCA therapy } \\
\hline 1 & $18 \cdot 3$ & $53 \cdot 2$ & $33 \cdot 2$ & $20 \cdot 0$ & $13 \cdot 3$ & $39 \cdot 9$ \\
\hline 2 & $8 \cdot 7$ & $47 \cdot 4$ & $39 \cdot 3$ & $8 \cdot 2$ & 21.9 & $25 \cdot 5$ \\
\hline 3 & $10 \cdot 8$ & $48 \cdot 5$ & $33 \cdot 3$ & $15 \cdot 2$ & $37 \cdot 7$ & $10 \cdot 8$ \\
\hline 4 & $76 \cdot 5$ & $31 \cdot 7$ & $12 \cdot 7$ & $19 \cdot 1$ & $7 \cdot 5$ & $24 \cdot 2$ \\
\hline 5 & $42 \cdot 2$ & $43 \cdot 6$ & $29 \cdot 6$ & $14 \cdot 0$ & $25 \cdot 6$ & $18 \cdot 0$ \\
\hline 6 & $2 \cdot 8$ & $46 \cdot 1$ & $0 \cdot 0$ & $46 \cdot 1$ & $8 \cdot 1$ & $38 \cdot 0$ \\
\hline 7 & $17 \cdot 2$ & $27 \cdot 4$ & $27 \cdot 4$ & $0 \cdot 0$ & $27 \cdot 4$ & $0 \cdot 0$ \\
\hline 8 & $64 \cdot 3$ & $47 \cdot 1$ & $34 \cdot 4$ & $12 \cdot 6$ & $10 \cdot 0$ & $37 \cdot 1$ \\
\hline 9 & $14 \cdot 1$ & $18 \cdot 0$ & $7 \cdot 3$ & $10 \cdot 7$ & $3 \cdot 2$ & $14 \cdot 8$ \\
\hline Mean (SD) & $28 \cdot 3(26 \cdot 4)$ & $40 \cdot 3(11 \cdot 8)$ & $24 \cdot 1(13 \cdot 9)$ & $16 \cdot 2(12 \cdot 7)$ & $17 \cdot 2(11 \cdot 5)$ & $23 \cdot 1(13 \cdot 6)$ \\
\hline Median & $17 \cdot 2$ & $46 \cdot 1$ & $33 \cdot 3$ & $14 \cdot 0$ & $13 \cdot 3$ & $24 \cdot 2$ \\
\hline
\end{tabular}

(lambda $=201 \mathrm{~nm}$ ), by comparison with the HPLC profile of a standard solution $(50 \mu \mathrm{M}$ of each conjugated bile acid in mobile phase).
The analytical characteristics of this method were tested on a patient serum at a concentration of 20 $\mu \mathrm{mol}$. The repeatability $(\mathrm{n}=5)$ is from $2 \cdot 5 \%$ for

Table 2 Absolute concentrations of individual bile acids before and under UDCA therapy

\begin{tabular}{|c|c|c|c|c|c|c|}
\hline \multirow[b]{2}{*}{ Patients (n) } & \multirow[b]{2}{*}{ Tot conj $\mu M$} & \multicolumn{5}{|c|}{ Primary bile acids } \\
\hline & & $\operatorname{Prim} \mu M$ & $C A \mu M$ & $C D C A \mu M$ & Tauro $C \mu M$ & GlycoC $\mu M$ \\
\hline \multicolumn{7}{|c|}{ Before UDCA therapy } \\
\hline 1 & $13 \cdot 1$ & $11 \cdot 1$ & $8 \cdot 3$ & $2 \cdot 8$ & $3 \cdot 3$ & $7 \cdot 8$ \\
\hline 2 & $5 \cdot 1$ & $4 \cdot 5$ & 1.2 & $3 \cdot 3$ & 1.6 & $3 \cdot 0$ \\
\hline 3 & $5 \cdot 6$ & $4 \cdot 5$ & $2 \cdot 2$ & $2 \cdot 4$ & $2 \cdot 7$ & 1.8 \\
\hline 4 & $56 \cdot 7$ & $43 \cdot 8$ & $31 \cdot 3$ & $12 \cdot 5$ & $19 \cdot 8$ & $24 \cdot 0$ \\
\hline 5 & $56 \cdot 1$ & $47 \cdot 7$ & $36 \cdot 1$ & $11 \cdot 6$ & $11 \cdot 1$ & $36 \cdot 6$ \\
\hline 6 & $10 \cdot 0$ & $6 \cdot 0$ & 2.9 & $3 \cdot 1$ & $3 \cdot 7$ & $2 \cdot 4$ \\
\hline 7 & $13 \cdot 8$ & 4.9 & $1 \cdot 0$ & 3.9 & $2 \cdot 0$ & $2 \cdot 9$ \\
\hline 8 & $93 \cdot 0$ & $82 \cdot 1$ & $42 \cdot 8$ & $39 \cdot 3$ & $28 \cdot 6$ & $53 \cdot 5$ \\
\hline 9 & $9 \cdot 2$ & $2 \cdot 4$ & 0.9 & $1 \cdot 6$ & 0.0 & $2 \cdot 4$ \\
\hline Mean (SD) & $29 \cdot 2(31 \cdot 5)$ & $23 \cdot 0(28 \cdot 3)$ & $14 \cdot 1(17 \cdot 4)$ & $8 \cdot 9(12 \cdot 1)$ & $8 \cdot 1(9 \cdot 9)$ & $14.9(18.9)$ \\
\hline Median & $13 \cdot 1$ & $6 \cdot 0$ & $2 \cdot 9$ & $3 \cdot 3$ & $3 \cdot 3$ & 3.0 \\
\hline \multicolumn{7}{|c|}{ Under UDCA therapy } \\
\hline 1 & $18 \cdot 3$ & 9.7 & $6 \cdot 1$ & $2 \cdot 4$ & $2 \cdot 4$ & $7 \cdot 3$ \\
\hline 2 & 8.7 & $4 \cdot 1$ & $3 \cdot 4$ & 1.9 & 1.9 & $2 \cdot 2$ \\
\hline 3 & $10 \cdot 8$ & $5 \cdot 3$ & 3.6 & $4 \cdot 1$ & $4 \cdot 1$ & $1 \cdot 2$ \\
\hline 4 & $76 \cdot 5$ & $24 \cdot 3$ & $9 \cdot 7$ & $5 \cdot 8$ & $5 \cdot 8$ & $18 \cdot 5$ \\
\hline 5 & $42 \cdot 2$ & $18 \cdot 4$ & $12 \cdot 5$ & 5.9 & $10 \cdot 8$ & $7 \cdot 6$ \\
\hline 6 & $2 \cdot 8$ & $1 \cdot 3$ & 0.0 & $1 \cdot 3$ & 0.2 & $1 \cdot 1$ \\
\hline 7 & $17 \cdot 2$ & $4 \cdot 7$ & $4 \cdot 7$ & 0.0 & 4.7 & 0.0 \\
\hline 8 & $64 \cdot 3$ & $30 \cdot 3$ & $22 \cdot 2$ & $8 \cdot 1$ & $6 \cdot 4$ & $23 \cdot 8$ \\
\hline 9 & $14 \cdot 1$ & $2 \cdot 5$ & 1.0 & 1.5 & 0.5 & $2 \cdot 1$ \\
\hline Mean (SD) & $28 \cdot 3(26 \cdot 4)$ & $11 \cdot 2(10 \cdot 5)$ & $7 \cdot 0(6 \cdot 9)$ & $4 \cdot 2(4 \cdot 7)$ & $4 \cdot 1(3 \cdot 3)$ & $7 \cdot 1(8 \cdot 5)$ \\
\hline Median & $17 \cdot 2$ & $5 \cdot 3$ & $4 \cdot 7$ & 1.7 & $4 \cdot 1$ & $2 \cdot 2$ \\
\hline
\end{tabular}




\begin{tabular}{|c|c|c|c|c|c|c|c|}
\hline \multicolumn{5}{|c|}{ Secondary bile acids } & \multicolumn{3}{|c|}{ Tertiary bile acids } \\
\hline Second $\%$ & $D C A \%$ & $L C A \%$ & TauroC $\%$ & GlycoC \% & $U D C A \%$ & TauroC \% & GlycoC \% \\
\hline $15 \cdot 4$ & $15 \cdot 4$ & 0.0 & $6 \cdot 2$ & 9.2 & $0 \cdot 0$ & 0.0 & 0.0 \\
\hline $12 \cdot 2$ & $12 \cdot 3$ & 0.0 & $12 \cdot 3$ & 0.0 & $0 \cdot 0$ & 0.0 & 0.0 \\
\hline $19 \cdot 1$ & $5 \cdot 0$ & $14 \cdot 1$ & 5.0 & $14 \cdot 1$ & 0.0 & 0.0 & $0 \cdot 0$ \\
\hline 21.7 & $3 \cdot 4$ & $18 \cdot 3$ & $3 \cdot 4$ & $18 \cdot 3$ & 1.0 & 0.0 & $1 \cdot 0$ \\
\hline $11 \cdot 8$ & $3 \cdot 1$ & $8 \cdot 8$ & 1.0 & $10 \cdot 8$ & $3 \cdot 2$ & 0.0 & $3 \cdot 2$ \\
\hline $15 \cdot 6$ & $15 \cdot 6$ & 0.0 & $6 \cdot 0$ & $9 \cdot 6$ & $24 \cdot 4$ & $24 \cdot 4$ & 0.0 \\
\hline $30 \cdot 7$ & $6 \cdot 5$ & $24 \cdot 1$ & $3 \cdot 6$ & $27 \cdot 0$ & $34 \cdot 1$ & 0.0 & $34 \cdot 1$ \\
\hline $5 \cdot 4$ & 0.8 & $4 \cdot 6$ & 0.0 & $5 \cdot 4$ & $6 \cdot 4$ & $6 \cdot 4$ & 0.0 \\
\hline $73 \cdot 7$ & $12 \cdot 2$ & $61 \cdot 5$ & 0.0 & $73 \cdot 7$ & 0.0 & $0 \cdot 0$ & 0.0 \\
\hline $22.9(20 \cdot 3)$ & $8 \cdot 3(5 \cdot 7)$ & $14 \cdot 6(19 \cdot 6)$ & $4 \cdot 2(3 \cdot 9)$ & $18 \cdot 7(22 \cdot 0)$ & $7 \cdot 7(12 \cdot 6)$ & $3 \cdot 4(8 \cdot 1)$ & $4 \cdot 3(11 \cdot 2)$ \\
\hline $15 \cdot 6$ & $6 \cdot 5$ & $8 \cdot 8$ & $3 \cdot 6$ & $10 \cdot 8$ & $1 \cdot 0$ & $0 \cdot 0$ & $0 \cdot 0$ \\
\hline $10 \cdot 3$ & $7 \cdot 2$ & $3 \cdot 1$ & $4 \cdot 5$ & $5 \cdot 8$ & $36 \cdot 5$ & 0.0 & $36 \cdot 5$ \\
\hline $35 \cdot 7$ & $4 \cdot 8$ & $30 \cdot 9$ & $4 \cdot 8$ & $30 \cdot 9$ & $16 \cdot 9$ & 0.0 & 16.9 \\
\hline $25 \cdot 5$ & 0.0 & $25 \cdot 5$ & 0.0 & $25 \cdot 5$ & $26 \cdot 0$ & 0.0 & $26 \cdot 0$ \\
\hline $14 \cdot 4$ & 0.0 & $14 \cdot 4$ & $0 \cdot 0$ & $14 \cdot 4$ & 53.9 & $14 \cdot 4$ & $39 \cdot 5$ \\
\hline $7 \cdot 8$ & $3 \cdot 3$ & $4 \cdot 5$ & 0.0 & $7 \cdot 8$ & $48 \cdot 6$ & $10 \cdot 0$ & $38 \cdot 6$ \\
\hline $15 \cdot 1$ & $15 \cdot 1$ & 0.0 & $15 \cdot 1$ & 0.0 & $38 \cdot 7$ & $38 \cdot 7$ & $0 \cdot 0$ \\
\hline $34 \cdot 0$ & $4 \cdot 1$ & $29 \cdot 8$ & $4 \cdot 1$ & $29 \cdot 8$ & $38 \cdot 6$ & $0 \cdot()$ & $38 \cdot 6$ \\
\hline $4 \cdot 2$ & 0.8 & $3 \cdot 4$ & 0.5 & $3 \cdot 7$ & $48 \cdot 7$ & 4.9 & $43 \cdot 9$ \\
\hline $27 \cdot 7$ & $10 \cdot 5$ & $17 \cdot 1$ & $0 \cdot 0$ & $27 \cdot 7$ & $54 \cdot 4$ & 11.0 & $43 \cdot 4$ \\
\hline $19 \cdot 4(11 \cdot 6)$ & $5 \cdot 1(5 \cdot 1)$ & $14 \cdot 3(12 \cdot 2)$ & $3 \cdot 2(5 \cdot 0)$ & $16 \cdot 2(12 \cdot 4)$ & $40 \cdot 2(12 \cdot 7)$ & $8 \cdot 8(12 \cdot 5)$ & $31.5(14 \cdot 7)$ \\
\hline $25 \cdot 5$ & $4 \cdot 1$ & $14 \cdot 4$ & 0.5 & $14 \cdot 4$ & $38 \cdot 7$ & 4.9 & $38 \cdot 6$ \\
\hline
\end{tabular}

TCDC to $4.9 \%$ to GLC. The coefficient of variation Recovery rates are about $85 \%(70 \%$ for TUDC to of the inter assay variability of the whole procedure $95 \%$ for GLC). The detection limit was $0.5 \mu \mathrm{mol} / \mathrm{l}$ ranged from $4 \cdot 5 \%$ for GCDC to $9 \cdot 1 \%$ to the GDC. for each conjugated bile acids.

\begin{tabular}{|c|c|c|c|c|c|c|c|}
\hline \multicolumn{5}{|c|}{ Secondary bile acids } & \multicolumn{3}{|c|}{ Tertiary bile acids } \\
\hline Second $\mu M$ & $D C A \mu M$ & $L C A \mu M$ & TauroC $\mu M$ & GlycoC $\mu M$ & $U D C A \mu M$ & Tauro $C \mu M$ & GlycoC $\mu M$ \\
\hline $2 \cdot 0$ & $2 \cdot 0$ & $0 \cdot 0$ & $0 \cdot 8$ & $1 \cdot 2$ & 0.0 & 0.0 & $0 \cdot 0$ \\
\hline $0 \cdot 6$ & $0 \cdot 6$ & 0.0 & $0 \cdot 6$ & $0 \cdot 0$ & $0 \cdot 0$ & $0 \cdot()$ & $0 \cdot 0$ \\
\hline $1 \cdot 1$ & $0 \cdot 3$ & $0 \cdot 8$ & $0 \cdot 3$ & $0 \cdot 8$ & 0.0 & 0.0 & $0 \cdot 0$ \\
\hline $12 \cdot 3$ & 1.9 & $10 \cdot 4$ & 1.9 & $10 \cdot 4$ & $0 \cdot 6$ & $0 \cdot()$ & $0 \cdot 6$ \\
\hline $6 \cdot 6$ & $1 \cdot 7$ & $4 \cdot 9$ & $0 \cdot 6$ & $6 \cdot 1$ & 1.8 & $0 \cdot 0$ & $1 \cdot 8$ \\
\hline $1 \cdot 6$ & 1.6 & $0 \cdot 0$ & $0 \cdot 6$ & $1 \cdot 0$ & $2 \cdot 4$ & $2 \cdot 4$ & $0 \cdot 0$ \\
\hline $4 \cdot 2$ & 0.9 & $3 \cdot 3$ & 0.5 & $3 \cdot 7$ & $4 \cdot 7$ & 0.0 & $4 \cdot 7$ \\
\hline $5 \cdot 0$ & $0 \cdot 7$ & $4 \cdot 3$ & 0.0 & $5 \cdot 0$ & $5 \cdot 9$ & 5.9 & $0 \cdot 0$ \\
\hline $6 \cdot 8$ & $1 \cdot 1$ & $5 \cdot 7$ & $0 \cdot 0$ & $6 \cdot 8$ & $0 \cdot 0$ & $0 \cdot()$ & $0 \cdot()$ \\
\hline $4 \cdot 5(3 \cdot 8)$ & $1 \cdot 2(0 \cdot 6)$ & $3 \cdot 3(3 \cdot 5)$ & $0 \cdot 6(0 \cdot 6)$ & $3 \cdot 9(3 \cdot 5)$ & $1 \cdot 7(2 \cdot 2)$ & $0.9(2 \cdot 0)$ & $0 \cdot 8(1 \cdot 6)$ \\
\hline $4 \cdot 2$ & $1 \cdot 1$ & $3 \cdot 3$ & $0 \cdot 6$ & $3 \cdot 7$ & 0.6 & $0 \cdot 0$ & $0 \cdot 0$ \\
\hline 1.9 & $1 \cdot 3$ & $0 \cdot 6$ & $0 \cdot 8$ & $1 \cdot 1$ & $6 \cdot 7$ & 0.0 & $6 \cdot 7$ \\
\hline $3 \cdot 1$ & 0.4 & $2 \cdot 7$ & $0 \cdot 4$ & $2 \cdot 7$ & 1.5 & $0 \cdot 0$ & 1.5 \\
\hline $2 \cdot 8$ & $0 \cdot 0$ & $2 \cdot 8$ & 0.0 & $2 \cdot 8$ & $2 \cdot 8$ & $0 \cdot 0$ & $2 \cdot 8$ \\
\hline $11 \cdot 0$ & $0 \cdot 0$ & $11 \cdot 0$ & $0 \cdot 0$ & $11 \cdot 0$ & $41 \cdot 2$ & 11.0 & $30 \cdot 2$ \\
\hline $3 \cdot 3$ & 1.4 & 1.9 & $0 \cdot 0$ & $3 \cdot 3$ & $20 \cdot 5$ & $4 \cdot 2$ & $16 \cdot 3$ \\
\hline $0 \cdot 4$ & 0.4 & $0 \cdot 0$ & 0.4 & $0 \cdot 0$ & $1 \cdot 1$ & $1 \cdot 1$ & $0 \cdot 0$ \\
\hline $5 \cdot 8$ & 0.7 & $5 \cdot 1$ & 0.7 & $5 \cdot 1$ & $6 \cdot 6$ & 0.0 & $6 \cdot 6$ \\
\hline $2 \cdot 7$ & $0 \cdot 5$ & $2 \cdot 2$ & $0 \cdot 3$ & $2 \cdot 4$ & $31 \cdot 3$ & $3 \cdot 1$ & $28 \cdot 2$ \\
\hline 3.9 & 1.5 & $2 \cdot 4$ & $0 \cdot 0$ & 3.9 & $7 \cdot 7$ & 1.6 & $6 \cdot 1$ \\
\hline $3 \cdot 9(3 \cdot 0)$ & $0.7(0 \cdot 6)$ & $3 \cdot 2(3 \cdot 3)$ & $0 \cdot 3(0 \cdot 3)$ & $3 \cdot 6(3 \cdot 2)$ & $13 \cdot 3(14 \cdot 5)$ & $2 \cdot 3(3 \cdot 6)$ & $10 \cdot 9(11 \cdot 4)$ \\
\hline $3 \cdot 1$ & 0.5 & $2 \cdot 4$ & $0 \cdot 3$ & $2 \cdot 8$ & $6 \cdot 7$ & $1 \cdot 1$ & $6 \cdot 6$ \\
\hline
\end{tabular}


Results are expressed as medians and means (SD). Wilcoxon's paired-sample test was used for statistical analysis.

\section{Results}

Under UDCA therapy, concentrations of serum bilirubin (53 (90) $v 19(17) \mu \mathrm{mol} / \mathrm{l})$, enzyme activities (expressed as a multiple of the upper limit of the reference range), alkaline phosphatase (7.3 (44) $v 2.7$ $(1.9))$, aspartate aminotransferase $(1.8(0.8) v 1.1$ $(0 \cdot 2))$, and gammaglutamyltransferase $(15 \cdot 8(5 \cdot 8) v$ $4 \cdot 7(2 \cdot 5))$ fell significantly $(\mathrm{p}<0 \cdot 01)$.

The effects of UDCA therapy on serum bile acid concentration and composition are shown in the Figure and in Tables 1 and 2. Total serum bile acid concentration did not change after one year of treatment. Total UDCA and glyco UDCA but not tauro UDCA concentrations increased significantly $(p<0.01)$; UDCA became the major bile acid species of the circulating endogenous pool. Primary bile acids, and glycoconjugates of primary bile acid fell significantly $(p<0.01)$ while there was no significant changes in the taurine conjugates. Concentrations of conjugates of the secondary bile acids (DCA and LCA) did not change significantly.

\section{Discussion}

Our study confirmed that oral administration of UDCA to patients with PBC induced marked changes in the circulating pool of endogenous bile acids together with improvement in liver function test values.

Enrichment of circulating bile acids to approximately $40 \%$ UDCA was associated with a decrease in the proportion of glycoconjugates of primary bile acid, cholic acid and CDCA. In contrast, the amount and proportion of circulating secondary bile acid that is, DCA and LCA were not modified by UDCA therapy. It cannot be excluded with certainty that some of the changes noted in bile acid composition might be caused by alteration in cholestyramine treatment. This seems improbable, however, as the changes observed in the two patients still ingesting cholestyramine after one year of UDCA therapy were similar to those noted in the patients who interrupted the regime.

The effect of UDCA therapy on the composition of biliary bile acid in gall stone patients has been previously studied."' At doses $>8-10 \mathrm{mg} / \mathrm{kg} / \mathrm{day}$, it has been shown that UDCA represents 40 to $60 \%$ of the biliary bile acids, a figure very similar to that obtained in our patients with PBC. The mechanism by which the circulating pool of endogenous bile acid is in part replaced by UDCA is unknown. The synthesis of CA and CDCA has been reported as being increased, unchanged, or decreased ${ }^{11-15}$; however, most of the studies have shown that the pool sizes of the two endogenous primary bile acids, cholic acid, and CDCA were markedly reduced and that their fractional turnover rates were increased. ${ }^{11} 15$ in These data, therefore, suggest that the mechanism of the increase in the proportion of UDCA conjugates and the reciprocal decrease of primary bile acid probably involve competitive inhibition between UDCA conjugates, and CDCA and cholic acid conjugates for ileal absorption. We found that the diminution of circulating cholic acid and CDCA was mainly because of a decrease in their glycine conjugates and not to a decrease in the taurine conjugates. These data further support the hypothesis of competition between GUDCA and the glyco conjugated cholic acid and CDCA at the active ileal transport site.

The absence of change in the serum concentrations and proportion of the conjugates of DCA and LCA suggest that the equilibrium between the rates of intestinal formation and absorption on one hand and the rate of hepatic removal on the other was unchanged by UDCA. Furthermore, as cholestasis apparently improved during UDCA therapy, the unchanged proportion of conjugated secondary bile acid together with the fall in the proportion of conjugated primary bile acid might be explained by an increased rate of formation and of colonic absorption of DCA and LCA from the increased amount of unabsorbed primary bile acid.

The simultaneous change in bile acid composition - that is, enrichment of circulating bile acid to $40 \%$ UDCA with a reciprocal decrease in the proportion of CDCA and cholic acid and improvement in liver function strongly suggests that endogenous primary bile acid rather than secondary bile acid may be partly responsible for hepatic injury occurring in PBC.

\section{References}

1 Poupon R, Chretien Y, Poupon RE, Ballet F, Calmus $Y$, Darnis F. Is ursodeoxycholic acid an effective treatment for primary biliary cirrhosis. Lancet 1987; i: 834-6.

2 Scholmerich J, Becher MS, Schmidt K, et al. Influence of hydroxylation and conjugation of bile salts on their membrane-damaging properties. Studies on isolated hepatocytes and lipid membrane vesicles. Hepatology 1984; 4: 661-6.

3 Hertz R, Paumgartner G. Preisig R. Inhibition of bile formation by high doses of taurocholate in the perfused rat liver. Scand J Gastroenterol 1975; 11: 741-6.

4 Drew R, Priestly BG. Choleretic and cholestatic effects of infused bile salts in the rat. Experientia 1979; 35: 80911. 
5 Fischer RL, Anderson DW. Boyer JL, et al. A prospective morphologic evaluation of hepatic toxicity of chenodeoxycholic acid in patients with cholelithiasis: the national cooperative gallstone study. Hepatology 1982; 2: 187-201.

6 Tint GS. Salen G, Colalillo A, et al. Ursodeoxycholic acid: a safe and effective agent for dissolving cholesterol gallstones. Ann Intern Med 1982; 97: 351-6.

7 Bachrach WH. Hofmann AF. Ursodeoxycholic acid in the treatment of cholesterol lithiasis. Dig Dis Sci 1982; 27: 833-56.

8 Street JM, Trafford DJH, Makin HLJ. Extraction and fractionation of bile acids and their conjugates using prepacked microparticulate silica cartridges (Sed-Pak Sil ${ }^{\mathrm{R}}$ and Bond-Elut ${ }^{\mathrm{RC}}$ 18). J Chromatogr 1985; 343: 259-70.

9 Dyfverman A, Sjovall J. Ion-pair extraction of bile acids with Lipidex gel. Anal Biochem 1983; 134: 303-8.

10 Tint GS, Salen G, Shefer S. Effect of ursodeoxycholic acid and chenodeoxycholic acid on cholesterol and bile acid metabolism. Gastroenterology 1986; 91: 1007-18.

11 Nilsell K, Angelin B, Leijd B, Einarsson K. Comparative effect of ursodeoxycholic acid and cheno- deoxycholic acid on bile acid kinetics and biliary lipid secretion. Gastroenterology 1983; 85: 1248-56.

12 Hardison WGM, Grundy SM. Effect of ursodeoxycholate and its taurine conjugate on bile acid synthesis and cholesterol absorption. Gastroenterology 1984; 87: 130-5.

13 Angelin B, Nilsell K, Einarsson K. Ursodcoxycholic acid treatment in humans: effects on plasma and biliary lipid metabolism with special reference to very low density lipoprotein triglyceride and bile acid kinetics. Eur J Clin Invest 1986; 16: 169-77.

14 Frenkel P, Lee D, Marks J, Gilmore C, Bonorris G, Schoenfield L. Effect of dict on bile acid kinetics and secretion of biliary lipids in patients treated with ursodeoxycholic acid [Abstract]. Gastroenterology 1982; 82: 1061 .

15 Roda E. Roda A. Sama C. et al. Effect of ursodeoxycholic acid administration on biliary lipid composition and bile acid kinctics in cholesterol gallstone patients. Dig Dis Sci 1979; 24: 123-8.

16 Lee D. Bonorris G, Cohen H, Gilmore C, Marks J, Schoenficld LJ. Effect of ursodeoxycholic acid on bile acid kinetics and hepatic lipid secretion [Abstract]. Hepatology 1981; 1: 36 . 